\title{
DEVELOPMENT OF A TIME-DEPENDENT 3-PARAMETER HELMERT DATUM TRANSFORMATION MODEL: A CASE STUDY FOR MALAYSIA
}

\author{
J. Gill, N. S. Shariff, K. M. Omar, A. H. M. Din, Z. M. Amin
}

Faculty of Geoinformation and Real Estate, Universiti Teknologi Malaysia, 81310 Skudai, Johor - jespal.g@gmail.com

KEY WORDS: GNSS, GDM2000, Tectonic Motion, Helmert Datum Transformation

\begin{abstract}
:
This paper aims to develop a time-dependent 3-parameter Helmert datum transformation model for Malaysia as a proposed solution to the current non-geocentric issue of the Geocentric Datum of Malaysia 2000 (GDM2000). Methodologically, the datum transformation models is categorised into three parts; firstly, the time-dependent aspect of the datum transformation model is determined using the tectonic motion velocities computed from linear least squares regression of the long-term time series of MyRTKnet stations positions from year December 2004 to 2014; whereby the station positions are obtained from high-precision daily double-difference processing of MyRTKnet and IGS stations via Bernese 5.0. Secondly, the 3 Helmert translation-only parameters, are derived between the original GDM2000 and GDM2000@2013 - the new datum coordinates which refers to ITRF2008 at epoch 3/7/2013 - via Bernese 5.0 software. Thirdly, a distortion model is computed in order to minimise the coordinate residuals between the 'processed' and 'transformed' new datum. The datum transformation model is then validated to determine the reliability of the model. The validation results show that the datum transformation model is within centimetre-level accuracy, i.e., below $3 \mathrm{~cm}$, over Malaysia for forward transformations to year 2014 and 2015. Therefore, this study anticipates that it will contribute as a feasible solution for the GDM2000 issue with consideration of the core concern: the complex tectonic motion of Malaysia.
\end{abstract}

\section{INTRODUCTION}

The Geocentric Datum of Malaysia 2000 (GDM2000) is established by the Department of Surveying Malaysia (DSMM) via the Malaysia Real-time Kinematic Network (MyRTKnet) geodetic infrastructure. Presently, the GDM2000 datum coordinates are referenced to ITRF2000 at epoch 2006. On the other hand, Malaysia has been affected by earthquakes over the years, primarily after the December 26, 2004 9.2 Mw SumatraAndaman earthquake; followed by the $8.6 \mathrm{Mw}$ Nias-Simeulue earthquake on March 28, 2005, the $8.5 \mathrm{Mw}$ Bengkulu earthquake on September 12, 2007 and the 8.6 Mw Northern Sumatra, or Indian Ocean, earthquake on April 11, 2012 (USGS, 2016).

As a result, the tectonic motion of Malaysia has displaced the datum coordinates; causing GDM2000 to be non-geocentric (see Shariff et al., 2014; Gill et al., 2015). Furthermore, the current International Terrestrial Reference Frame (ITRF) is ITRF2008 (with respect to the period in which this study was carried out) which is, in fact, an enhancement to ITRF2000. Hence, these would create issues such as mismatch of base maps and geospatial database, coordinate bias due to inconsistency with satellite orbits, and decreased accuracy of reference stations coordinates which in turn affects the legal traceability of the coordinates.

Therefore, GDM2000 needs to be updated in order for the issues to be rectified. However, due to tectonic motion, the geodetic datum would need to be updated over time. This then would result in an array of epochs for the geodetic datum causing confusion at the user level. Hence, a time-dependent datum transformation model would be most appropriate - as users would update the geodetic datum to a desired epoch with reference to the official datum epoch; thus, the aim of this study: to develop a time-dependent datum transformation model for Malaysia.

In this study, the well-known Helmert datum transformation model is chosen with only its 3 translation parameters selected. The translation parameters are exclusively chosen as the transformation is between satellite datums, i.e., GDM2000 and GDM2000@2013 - both referenced to the ITRF; hence, theoretically, there should not be significant rotation and scale values, whereby the latter is predominantly dependent on the changes in ellipsoid. Moreover, a 3-parameter transformation is simple to realise and update, especially in terms of its timedependent aspect, of which is represented by the tectonic motion velocities of Malaysia in this study. It should be noted that the measured tectonic motion is with regard to the crustal motion, i.e., within the Sunda block.

This paper will firstly describe the methodological facet in developing the time-dependent 3-parameter Helmert transformation model for Malaysia. Next, the tectonic motion analysis and datum transformation model's validation results are discussed. This paper will attempt to further improve the tectonic motion analysis by Gill et al. (2015) with the addition of 2014 MyRTKnet data; however, less emphasis will be given as it slightly deviates from the aim of this paper. Lastly, the conclusion and final remarks are outlined. All in all, this study anticipates that it will contribute as a solution for the GDM2000 issue with consideration of the core concern: the complex tectonic motion of Malaysia. 
The International Archives of the Photogrammetry, Remote Sensing and Spatial Information Sciences, Volume XLII-4/W1, 2016 International Conference on Geomatic and Geospatial Technology (GGT) 2016, 3-5 October 2016, Kuala Lumpur, Malaysia

\section{METHODOLOGY FOR THE DEVELOPMENT OF A TIME-DEPENDENT 3-PARAMETER HELMERT DATUM TRANSFORMATION MODEL}

Several steps were implemented for the development of the model. Firstly, the time-dependent aspect of the datum transformation model was determined using the tectonic motion velocities computed from linear least squares regression of the long-term time series of MyRTKnet stations positions from year December 2004 to 2014; whereby the station positions were obtained from high-precision daily double-difference GPS processing of MyRTKnet and IGS stations via Bernese 5.0. The time series was plotted and linear least squares regression was computed via GPS Interactive Time Series Analysis software (GITSA) (Goudarzi et al., 2013). A velocity vector map was then plotted in order to visualise the tectonic motion of Malaysia via Generic Mapping Tools (GMT) (Wessel and Smith, 1998). Secondly, the 3 translational parameters, were derived between the original GDM2000 and GDM2000@2013 - the new datum coordinates which refers to ITRF2008 at epoch 3/7/2013 - via Bernese 5.0 software (Dach et al., 2007). Thirdly, a distortion model was computed in order to minimise the coordinate residuals between the original and new datum. The datum transformation model was then validated with coordinates at epoch $9 / 7 / 14,1 / 4 / 15$, and $1 / 7 / 15$ in order to determine the reliability of the model.

\subsection{High-precision GPS processing}

To estimate daily solutions of the MyRTKnet stations, Bernese version 5.0 was used by employing its double difference quasiionosphere free (QIF) strategy. 65 MyRTKnet stations and 24 IGS stations were chosen with GNSS data spanning from December 2004 to December 2014. Only 15 out of the 24 IGS stations were selected (see figure 1) as fiducial stations for datum definition as they represented stable motions throughout the data time span. The processing strategy and parameters adopted are given in table 1 .

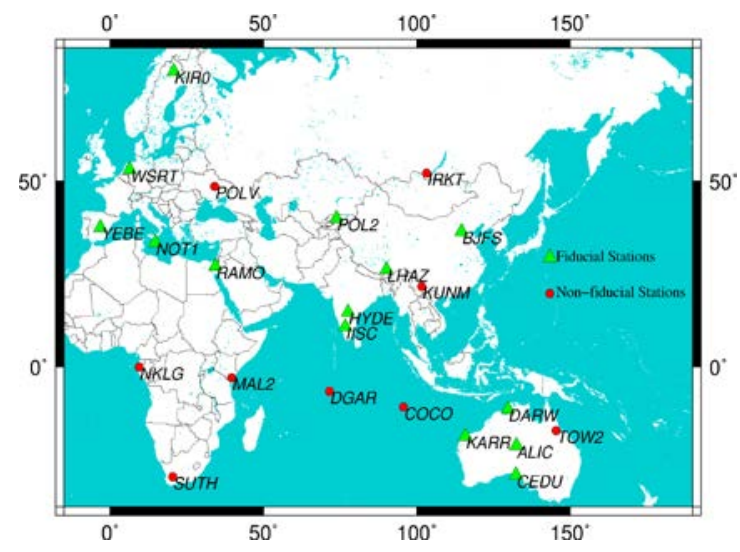

Figure 1. Fiducial and non-fiducial IGS stations selected for Bernese processing

\begin{tabular}{|l|l|}
\hline \multicolumn{1}{|c|}{ Processing Parameters } & \multicolumn{1}{c|}{ Processing Strategy } \\
\hline BPE Process Control File & RNX2SNX.PCF \\
\hline Elevation Cut-off Angle & $10^{\circ}$ \\
\hline Sampling Rate & 30 seconds \\
\hline Orbits & IGS Final Orbit (.SP3) \\
\hline Antenna Phase Centre & PHAS_COD.I08 \\
\hline Datum Definition & $\begin{array}{l}\text { Minimum constrained to } \\
\text { ITRF2008 (translation fixed) }\end{array}$ \\
\hline
\end{tabular}

\begin{tabular}{|l|l|}
\hline Ocean Loading Model & FES2004 \\
\hline Ionosphere & $\begin{array}{l}\text { Double-difference Ionospheric- } \\
\text { Free (IF) linear Combination (L3) }\end{array}$ \\
\hline Ambiguity Resolution & $\begin{array}{l}\text { Fixed, by QIF strategy with } \\
\text { baselines < 2000km }\end{array}$ \\
\hline $\begin{array}{l}\text { A priori model } \\
\text { (Troposphere) }\end{array}$ & $\begin{array}{l}\text { A-priori Saastamoinen model } \\
\text { (hydrostatic part) with dry Niell } \\
\text { mapping function }\end{array}$ \\
\hline $\begin{array}{l}\text { Zenith Path Delay } \\
\text { Parameters }\end{array}$ & $\begin{array}{l}\text { Mapping Function: Wet Niell } \\
\text { Parameter Spacing: 2 hours }\end{array}$ \\
\hline
\end{tabular}

Table 1. Processing strategy and parameters used for Bernese processing

Finally, the daily solutions from $1^{\text {st }}$ December 2004 to $31^{\text {st }}$ December 2014 were plotted in a time series of station positions as a preliminary investigation into the trend, i.e., tectonic motion of Malaysia.

\subsection{Velocity vector estimation and mapping}

After the daily solutions were estimated, a time series of daily solutions for the selected MyRTKnet stations were plotted using GITSA, a software developed by Goudarzi et al. (2013) for time series analysis using MATLAB. Once each station's time series was plotted, the outliers were removed at 99\% confidence level within GITSA as it may affect the linear regression line later for estimating the velocity vectors. The determination of velocity vectors from linear least squares regression must fulfil two criteria: (1) minimum of 2.5 years solution in order to reduce annual and semi-annual effects in geodetic time series, of which will cause biased estimated velocities (Blewitt and Lavallée, 2002), and (2) time series with long data gaps, i.e., few months, are not chosen to estimate the velocity vectors. Hence, steadystate periods of at least 2.5 years were chosen to compute the velocity vectors. These steady-state periods are: the 2008 to 2011 period which represents the post-seismic tectonic motion after the pivotal 2004 Sumatra-Andaman earthquake, and the October 2012 to 2014 period which represents the post-seismic motion after the 2012 Northern Sumatra earthquake. Refer to figure 2 for visualisation and explanation. Once the velocity vectors for each station is computed, they were plotted on map using GMT. It is noted that the velocities are in centimetre per year $(\mathrm{cm} / \mathrm{yr})$ and in Cartesian system, but converted to metre per year $(\mathrm{m} / \mathrm{yr})$ for the datum transformation model.

There are a few reasons why the tectonic velocity vectors are required for the datum transformation model; primarily, it is to compute the time-dependent aspect, other reasons include: (1) determination of size of the area of transformation (see Mitsakaki, 2004), and (2) common points' selection based on conformality (see Collier, 2002). These will be discussed later.

\subsection{Time-dependent aspect estimation for the 3-parameter datum transformation model}

The concept of utilising tectonic motion for the time-dependent aspect was adapted from Stanaway and Roberts (2009) who used Euler pole rotations for their 3-parameter datum transformation model for Australia. The time-dependent aspect is commonly known as the parameters' rates of change. The rates of change were determined by computing the average velocities of the MyRTKnet stations that were selected as common points for the transformation. 
2.4 3-parameter estimation of the Helmert datum transformation model: As for the 3-parameter estimation, there are a few components that must be taken into account before estimating them. Firstly, the new datum coordinates must be realized. The method to realize a datum is slightly complex. There is no specific length of time for realizing a new datum, it can be from a few years (see Mateo and Mackern, 2012;
Habrich, 2007) to a week or two (see Gianniou, 2010). In this study, 1 week data, i.e., GPS week 1747 , was processed and combined to realise the new datum at epoch 2013.5047 or 3/7/2013 - termed GDM2000@2013. This week was selected as it was a stable week, i.e., coordinates repeatability below 1 $\mathrm{cm}$ and $3 \mathrm{~cm}$ for the horizontal and vertical components, respectively.

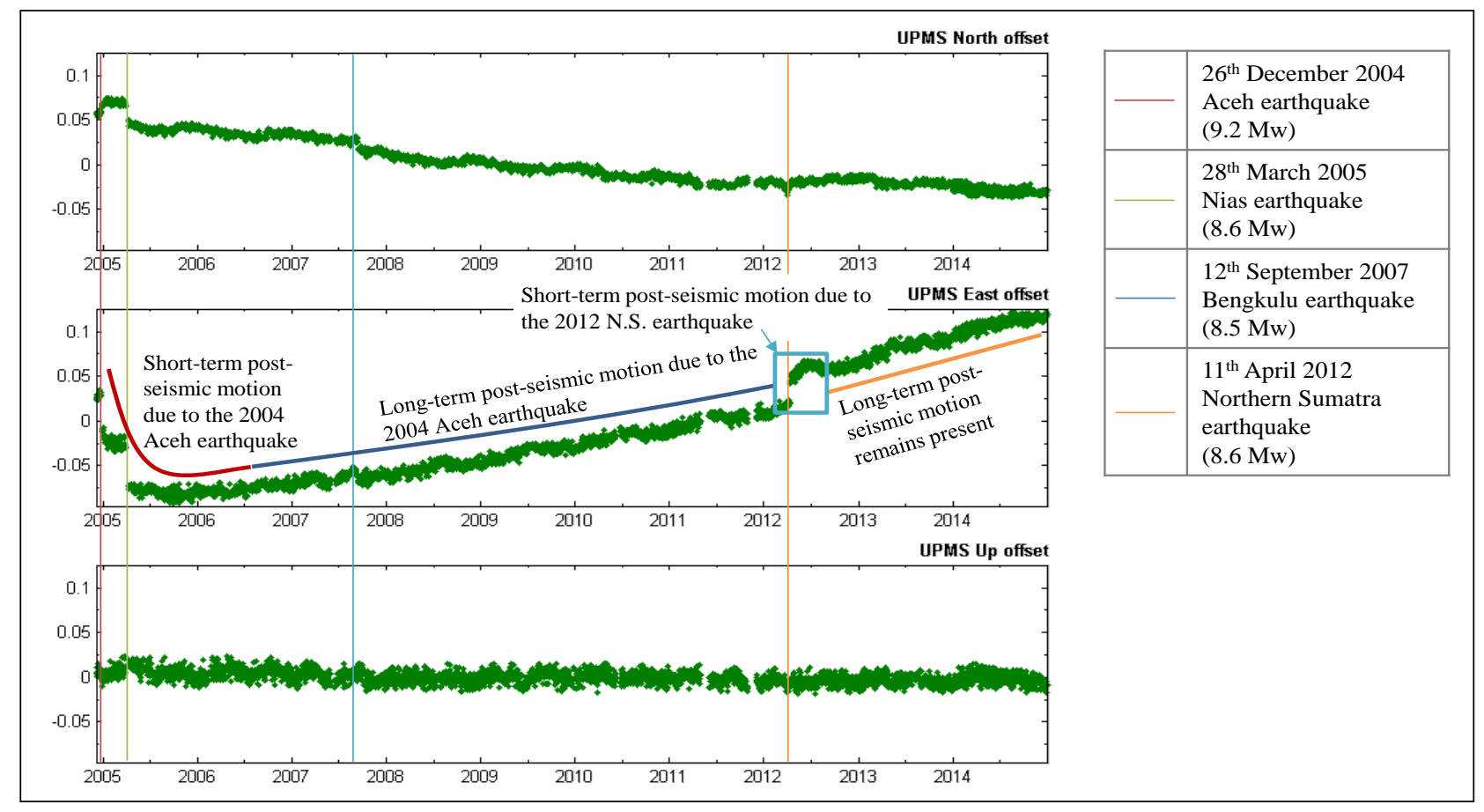

Figure 2. Time series of station UPMS (University Putra Malaysia) depicting the 2008-2011 and Oct-2012-2014 steady-state periods, and the post-seismic and co-seismic effects due to earthquakes. UPMS was chosen as it is affected by all the aforementioned earthquakes. The North and East components are in topocentric (local) system, while the Up component is the ellipsoidal heights. Though the time series is self-explanatory, for a more complete elaboration, refer to Gill et al. (2015)

The datum is realized with the same procedure as section 2.1, i.e., minimum constrained to the IGS coordinates. The IGS coordinates employed was from the published IGS weekly datum coordinates which are in SINEX format and available at ftp://cddis.gsfc.nasa.gov/gps/products. Hence, the new datum refers to the IGb08 frame which is basically a subset of ITRF2008. Refer Rebischung (2012) for more information on IGb08 and its weekly published coordinates. Reliability of the new datum coordinates was achieved by obtaining close-to-zero values for the 7 datum transformation parameters between IGS processed/combined coordinates and published weekly coordinates (Habrich, 2007) (shown later).

Once GDM2000@2013 was realised, the next component was the common points' selection. The selected common points must be conformal; particularly, with respect to this study, they must have almost similar velocity vectors in order to minimise the abortion of errors into the parameters. With the common points' selected, the 3 datum transformation parameters was then derived between GDM2000 and GDM2000@2013 via Bernese's Helmert program.

\subsection{Distortion model determination}

A distortion model that accommodates the coordinate residuals between the processed/combined coordinates and transformed coordinates of GDM2000@2013 was then estimated. The transformed coordinates are basically coordinates obtained after applying the 3 transformation parameters to the original GDM2000 coordinates. In other words, the distortion model functions to shift the transformed coordinates into the processed/combined datum coordinates so as to avoid any large discrepancies in the results. The distortion model is constant, i.e., it can be applied after the transformation at any epoch.

\subsection{Time-dependent 3-parameter Helmert Datum transformation model equation}

The equation for employment of the 3 datum transformation parameters, their rates of change and the distortion model is as follows:

$$
\left(\begin{array}{l}
X \\
Y \\
Z
\end{array}\right)_{T}=\left(\begin{array}{l}
X \\
Y \\
Z
\end{array}\right)_{S}+\left(\begin{array}{c}
T X \\
T Y \\
T Z
\end{array}\right)+\left[\begin{array}{l}
V X \\
V Y \\
V Z
\end{array}\right]\left(t-t_{o}\right)-\left(\begin{array}{l}
\Delta X \\
\Delta Y \\
\Delta Z
\end{array}\right)_{d}
$$

Whereby, the $\mathrm{T}$ and S subscripts depicts the Target and Source 3D Cartesian coordinates, and $(T X, T Y, T Z)$ are the translation components, $(V X, V Y, V Z)$ are the averaged station velocities (rates of change), $\left(\Delta X_{d}, \Delta Y_{d}, \Delta Z_{d}\right)$ are the distortion model for each MyRTKnet station, and $t$ and $t_{o}$ denotes the target and reference, i.e., 2013.5027, epoch in decimal years, respectively. 


\subsection{The datum transformation model validation}

Three validation epochs were chosen to realize a new set of coordinates following the same datum realization procedure as section 2.4. These epochs are 2014.5912 (9/7/14), 2015.2479 (1/4/15), and 2015.4973 (1/7/15). The model from section 2.6 is employed to transform the original GDM2000 coordinate to the chosen validation epochs and compared with the processed/combined coordinates. The average Helmert residuals in local $(\mathrm{N}, \mathrm{E}, \mathrm{U})$ coordinate system and the 3 Helmert parameters will be used as the results for the validation. It is noted that only epoch 2014.5912 uses 1 week data, i.e., GPS week1800, for it coordinates determination. The 2015 MyRTKnet data was not available during this study; hence, only 1 day data was utilised. The 2 days MyRTKnet data for the 2015 validation was downloaded from the E-biz JUPEM Geoportal.

\section{RESULTS AND DISCUSSION}

The results and discussion are categorised to three parts: (1) the tectonic motion analysis, (2) the time-dependent 3-parameter Helmert datum transformation model estimation, and (3) the validation of the time-dependent 3-parameter Helmert datum transformation model.

\subsection{The tectonic motion analysis of Malaysia}

From the Bernese processing of daily solutions between years December 2004 and 2014, most daily solutions provided excellent ambiguity resolution, on average, above $75 \%$. Positional RMS error for MyRTKnet stations were mostly below $1 \mathrm{~mm}$ for the horizontal component and $1.5 \pm 0.5 \mathrm{~mm}$ for the height component.

The tectonic motion is categorised into regions: North-west, North-east (east-coast), Central (west-coast), and South Peninsular Malaysia, and Sabah and Sarawak for East Malaysia. The North-west Peninsular region consists of stations at Perlis, Kedah, Perak, Perak-Kelantan border, and stations nearby the Perak-Selangor border (stations ARAU, UUMK, LGKW, SIK1, SGPT, GRIK, BABH, LASA, GMUS, PUSI, PUPK, SBKB, and BEHR), the North-east region consists of stations at Kelantan, Terengganu, and Pahang (stations CAME, GETI, AYER, PASP, SETI, KUAL, TERI, MUKH, LIPI, JRNT, CENE, SRIJ, PEKN, TLOH, and MUAD), the Central region consists of stations at Selangor and Negeri Sembilan (stations BENT, MERU, UPMS, KLAW, BAHA, and PDIC), and the South Peninsular region consists of Melaka and Johor (stations SEG1, KROM, JUML, GAJA, MERS, PRTS, SPGR, TGRH, JHJY, KUKP, and TGPG).
Sarawak consists stations SEMA, UMAS, SARA, KAPI, BIN1, NIAH, and MRDI, while Sabah consists stations BEAU, KENI, TMBN, UMSS, RANA, BELU, MRDU, KUDA, MTAW, DATU, and SEMP. The division into regions is in fact due to the resulting complex motion after the 2004 Sumatra-Andaman earthquake. The average horizontal velocities is tabulated in table 2.

\begin{tabular}{|c|c|c|}
\hline Region & $\begin{array}{l}\text { Average Horizontal Velocity } \\
\quad(2008-2011)(\mathrm{cm} / \mathrm{yr})\end{array}$ & $\begin{array}{l}\text { Direction } \\
\text { (Degrees) }\end{array}$ \\
\hline $\begin{array}{l}\text { North-west } \\
\text { Peninsular } \\
\text { Malaysia }\end{array}$ & $1.59 \pm 0.02$ & 132.0767 \\
\hline $\begin{array}{l}\text { North-east } \\
\text { Peninsular } \\
\text { Malaysia }\end{array}$ & $1.95 \pm 0.02$ & 112.8134 \\
\hline $\begin{array}{l}\text { Central } \\
\text { Peninsular } \\
\text { Malaysia }\end{array}$ & $2.06 \pm 0.02$ & 112.3999 \\
\hline $\begin{array}{l}\text { South } \\
\text { Peninsular } \\
\text { Malaysia }\end{array}$ & $2.34 \pm 0.02$ & 111.1570 \\
\hline Sarawak & $2.75 \pm 0.02$ & \multirow{2}{*}{110.8854} \\
\hline Sabah & $2.69 \pm 0.02$ & \\
\hline
\end{tabular}

Table 2. Averaged horizontal velocities of Malaysia by region and their directions for the 2008-2011 period

Based on table 2 and figure 3, the tectonic motion is almost non-uniform over Peninsular Malaysia. The directions of the North-east, Central, and South Peninsular Malaysia regions are almost similar with East Malaysia, while the North-west Peninsular Malaysia region is dissimilar to them. In terms of velocities, it is clear that a velocity vector gradient along Peninsular Malaysia is present. As for East Malaysia, the tectonic motion is more uniform comparatively, as the directions and velocities are almost similar (maximum difference of $4.4 \mathrm{~mm}$ between the highest, $2.97 \mathrm{~cm} / \mathrm{yr}$ at UMSS and lowest, $2.53 \mathrm{~cm} / \mathrm{yr}$ at BEAU, velocities).

The considerable difference between the North-west region and the rest of Peninsular Malaysia may be due to a so-called 'pull' towards the epicentre of the 2004 earthquake, causing the velocities to decelerate. In general, from 2008 to 2011, Peninsular and East Malaysia moves south-east at an average horizontal velocity of $1.91 \mathrm{~cm} / \mathrm{yr}$ and $2.72 \mathrm{~cm} / \mathrm{yr}$, respectively. As a result of the 2004 earthquake, Peninsular Malaysia decelerated and experienced a velocity vector gradient. 


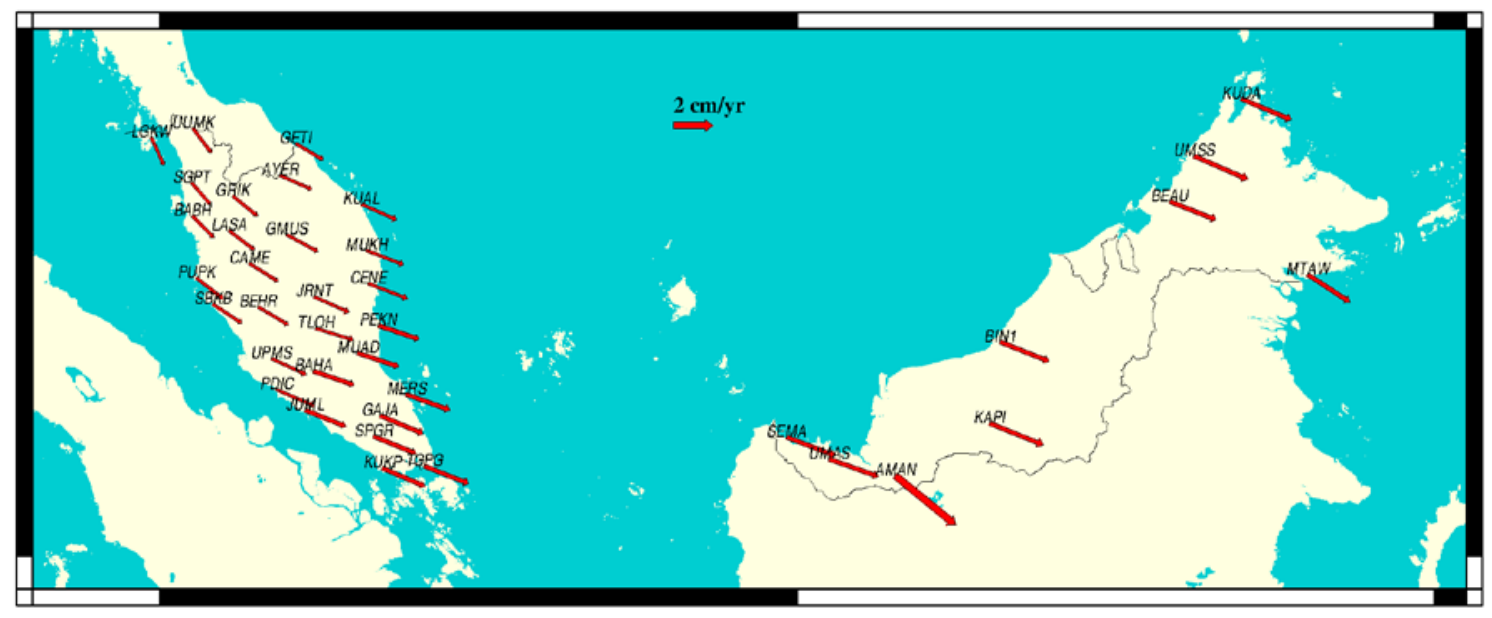

Figure 3. MyRTKnet velocity vector map for the 2008 to 2011 period. Note that fewer stations are displayed as the station names and arrows will overlap one another. As for East Malaysia, most stations began operation in April 2009; hence, they are not selected for velocity vector determination. Station AMAN has a different direction and velocity as it experiences severe subsidence

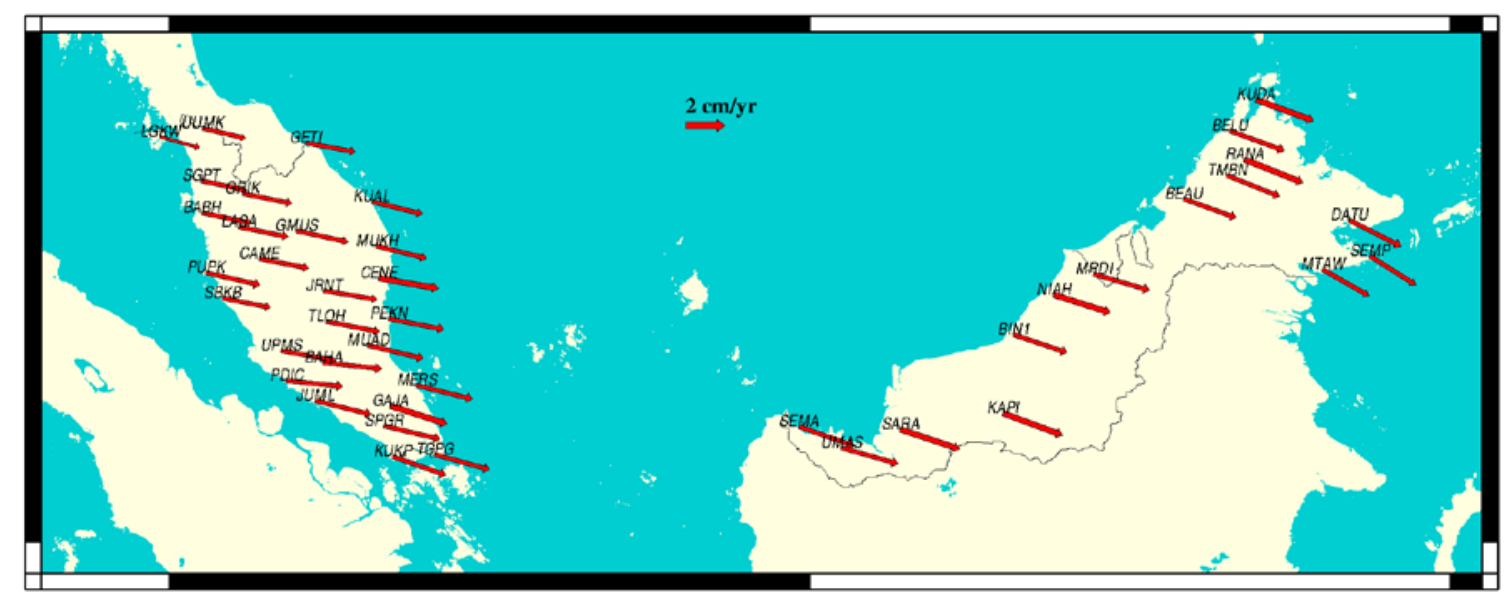

Figure 4. MyRTKnet velocity vector map for the Oct-2012 to 2014 period. Note that fewer stations are displayed as the station names and arrows will overlap one another

Next, the average horizontal velocities after the 2012 Northern Sumatra earthquake, i.e., the Oct-2012 to 2014 period, is given in table 3. Table 3 follows the same categorisation as table 2.

\begin{tabular}{|l|c|c|}
\hline \multicolumn{1}{|c|}{ Region } & $\begin{array}{c}\text { Average Horizontal Velocity } \\
\text { (Oct-2012 - 2014) (cm/yr) }\end{array}$ & $\begin{array}{c}\text { Direction } \\
\text { (Degrees) }\end{array}$ \\
\hline $\begin{array}{l}\text { North-west } \\
\text { Peninsular } \\
\text { Malaysia }\end{array}$ & $2.48 \pm 0.04$ & 102.2106 \\
\hline $\begin{array}{l}\text { North-east } \\
\text { Peninsular } \\
\text { Malaysia }\end{array}$ & $2.74 \pm 0.04$ & 101.5410 \\
\hline $\begin{array}{l}\text { Central } \\
\text { Peninsular } \\
\text { Malaysia }\end{array}$ & $2.86 \pm 0.04$ & 99.0948 \\
\hline $\begin{array}{l}\text { South } \\
\text { Peninsular } \\
\text { Malaysia }\end{array}$ & $2.90 \pm 0.04$ & 105.5699 \\
\hline Sarawak & $2.99 \pm 0.04$ & 108.3139 \\
\hline Sabah & $2.89 \pm 0.04$ & 112.9240 \\
\hline
\end{tabular}

Table 3. Averaged horizontal velocities of Malaysia by region and their directions for the Oct-2012-2014 period.
Based on table 3 and figure 4, the tectonic motion of Peninsular Malaysia is almost uniform compared to the 2008-2011 period. The directions of the Peninsular Malaysia regions are almost uniform with East Malaysia. The North-west region velocity vectors also seems to be more consistent with the rest of Malaysia. In terms of velocities, the velocity vectors gradient along Peninsular Malaysia is much less visible; though there are slight differences $-\sim 3 \mathrm{~mm}$ on average - between the regions (see table 3) - evidently, there still exists a minor deceleration in the North-west region. This suggests that the post-seismic effect of 2004 earthquake is still present. As for East Malaysia, the tectonic motion continues a uniform motion alike the previous period, but with small differences in direction. Only 2 years and 3 months data were used which would not generate concrete results as the time series contains seasonal effects - as can be seen from the increase in the velocities standard error. In general, from Oct-2012 to 2014, Peninsular and East Malaysia moves south-east at an average horizontal velocity of 2.72 $\mathrm{cm} / \mathrm{yr}$ and $2.93 \mathrm{~cm} / \mathrm{yr}$, respectively.Nonetheless, this length is sufficient for the study on the datum transformation model. It is stressed here that this finding does not assume that the postseismic deformation of Oct-2012 to 2014 is minimum and can be neglected; the post-seismic motion is still on going and it is adopted as part of the time-dependent transformation model. 


\subsection{The time-dependent 3-parameter Helmert datum transformation model}

Firstly, the new datum is realized with reference to IGb08 at epoch 2013.5027 (3/7/2013). Table 4 provides the agreement between the processed/combined IGS coordinates and the weekly IGb08 frame coordinates at epoch 2013.5027. Therefore, due to the close-to-zero values for the transformation parameters, it is evident that the MyRTKnet stations are successfully tied to the IGb08 frame at epoch 2013.5027 as well. Note that all 7 parameters are used to validate the new datum as the realization of international reference frames takes into account all these parameters.

\begin{tabular}{|l|r|r|}
\hline \multicolumn{1}{|c|}{ Parameters } & \multicolumn{1}{c|}{$\begin{array}{c}\text { Peninsular } \\
\text { Malaysia }\end{array}$} & \multicolumn{1}{c|}{$\begin{array}{c}\text { East } \\
\text { Malaysia }\end{array}$} \\
\hline Translation in X (mm) & $-0.9 \pm 1.7$ & $1.9 \pm 2.0$ \\
\hline Translation in Y (mm) & $-1.1 \pm 1.5$ & $-1.9 \pm .7$ \\
\hline Translation in Z (mm) & $0.5 \pm 1.9$ & $0.4 \pm 2.2$ \\
\hline Rotation around X-axis & 0.00004 & 0.00004 \\
(seconds) & \pm 0.00008 & \pm 0.00009 \\
\hline Rotation around Y-axis & -0.00002 & -0.00001 \\
(seconds) & \pm 0.00006 & \pm 0.00006 \\
\hline Rotation around Z-axis & 0.00004 & 0.00015 \\
(seconds) & \pm 0.00006 & \pm 0.00007 \\
\hline Scale Factor (ppm) & 0.0002 & 0.0004 \\
\hline
\end{tabular}

Table 4. Transformation parameters between processed/combined IGS coordinates and the weekly IGb08 frame coordinates at epoch 2013.5027

Secondly, since the datum transformation model covers the transformation from epoch 2006 to 2013, the 2008-2011 period has a significant role in determining the size of transformation area and selection of common points. As for the size of transformation area, it is evident that Peninsular and East Malaysia were moving differently before the 2012 Northern Sumatra earthquake based on section 3.1. Therefore, two separate datum transformation models are required. As for the selection of common points, Peninsular Malaysia has an nonuniform pattern, which results in tedious selection of common points. Initially, stations from the central region of Peninsular Malaysia was selected as common points due to the fact it has the most stations available that are conformal; then, by trialand-error, the common points with the least Helmert residuals and transformation parameters standard errors were selected. East Malaysia followed the same trial-and-error process for common points' selection. Note that the common points' selection was based on the transformation between GDM2000 and GDM2000@2013. Next, the 3 transformation parameters are derived.

The distortion model is then computed, i.e., the coordinates discrepancy between the processed/combined coordinates and the transformed coordinates of GDM2000@2013 for each MyRTKnet station. The distortion model is absolutely necessary due to the large coordinate discrepancy of the North-west stations which had discrepancies up to $5 \mathrm{~cm}$ for station ARAU and UUMK for the $\mathrm{X}$ component. The distortion model contains the coordinate differences in Cartesian system for each MyRTKnet station; it is not an average value due to the large coordinate differences between the some regions of Peninsular Malaysia, namely the North-west region.

Lastly, the 3-parameters' rates of change are determined. The rates of change for Peninsular Malaysia is the average of the selected common points' velocities. While for East Malaysia, many of the common points were not included in the 65 MyRTKnet stations selection from section 2.1; hence, other station were included for computing the average velocity. The other stations could be used for East Malaysia due to the fact that it has a more uniform motion compared to Peninsular Malaysia. The Oct-2012 to 2014 period was chosen for the rates of change determination, as it would suffice for forward transformations. It is noted that this datum transformation model is unsuitable for backward transformations, i.e., before epoch 2013.5027.

The time-dependent 3-parameter datum transformation model results are shown in table 5 for Peninsular Malaysia, and table 6 for East Malaysia; with their rates of change and selected common points. Table 7 shows the stations used for computing the average velocities, i.e., rates of change.

With the time-dependent 3-parameter datum transformation model for Malaysia developed, the next step is to validate the model in order to determine the reliability and accuracy of the model.

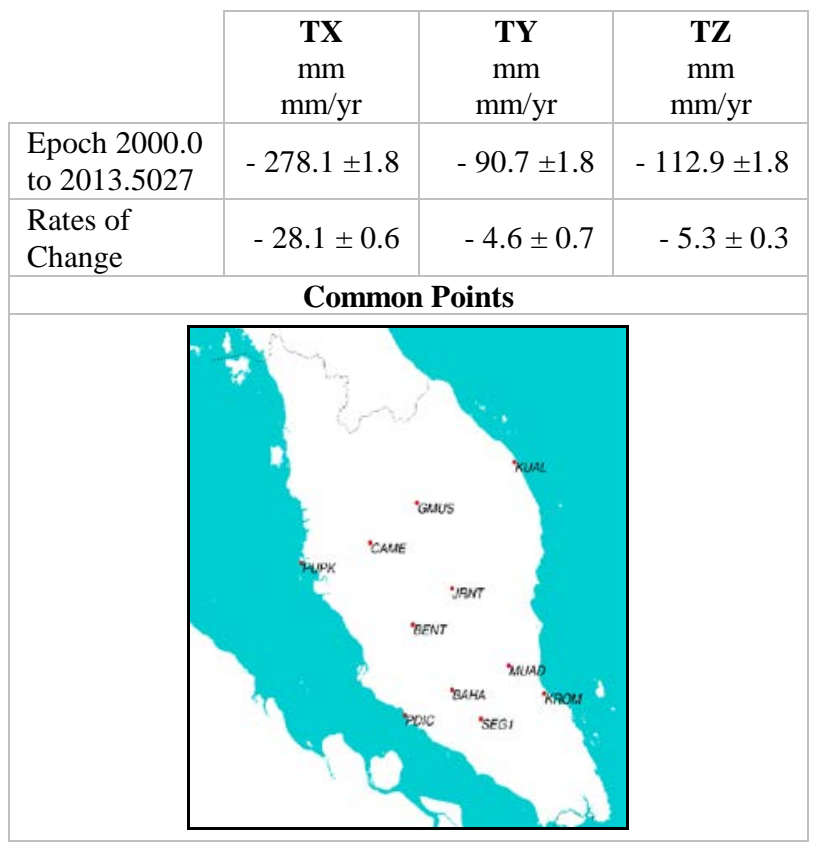

Table 5. The time-dependent 3-parameter datum transformation model values for Peninsular Malaysia with its selected common points

\begin{tabular}{|l|c|c|c|}
\cline { 2 - 4 } \multicolumn{1}{c|}{} & \multicolumn{1}{c|}{$\begin{array}{c}\text { TX } \\
\mathrm{mm} \\
\mathrm{mm} / \mathrm{yr}\end{array}$} & $\begin{array}{c}\mathbf{T Y} \\
\mathrm{mm} \\
\mathrm{mm} / \mathrm{yr}\end{array}$ & $\begin{array}{c}\mathbf{T Z} \\
\mathrm{mm} \\
\mathrm{mm} / \mathrm{yr}\end{array}$ \\
\hline $\begin{array}{l}\text { Epoch } 2000.0 \\
\text { to 2013.5027 }\end{array}$ & $-96.8 \pm 1.7$ & $-49.2 \pm 1.7$ & $-6.3 \pm 1.7$ \\
\hline $\begin{array}{l}\text { Rates of } \\
\text { Change }\end{array}$ & $-26.4 \pm 0.6$ & $-11.7 \pm 0.7$ & $-9.7 \pm 0.3$ \\
\hline
\end{tabular}

Common Points 


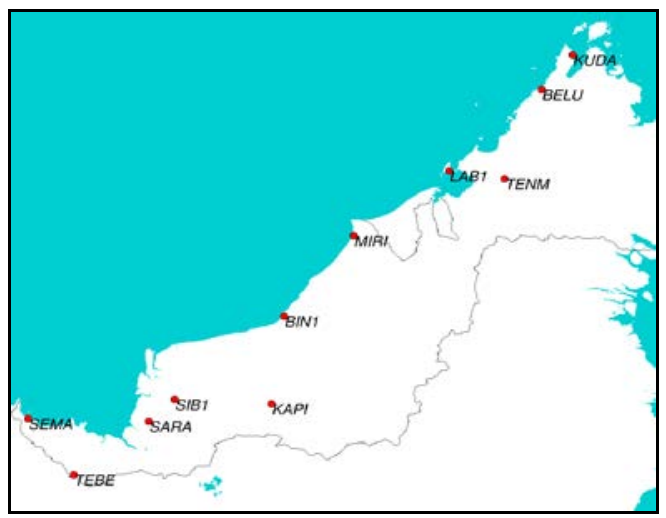

\begin{tabular}{|c|c|c|c|}
\hline Station & VX (m/yr) & VY (m/yr) & VZ (m/yr) \\
\hline \multicolumn{4}{|c|}{ Peninsular Malaysia } \\
\hline BAHA & $-0.0294 \pm 0.0006$ & $-0.0062 \pm 0.0007$ & $-0.0042 \pm 0.0003$ \\
\hline BENT & $-0.0290 \pm 0.0006$ & $-0.0030 \pm 0.0007$ & $-0.0055 \pm 0.0003$ \\
\hline CAME & $-0.0262 \pm 0.0006$ & $-0.0028 \pm 0.0007$ & $-0.0056 \pm 0.0003$ \\
\hline GMUS & $-0.0273 \pm 0.0006$ & $-0.0044 \pm 0.0007$ & $-0.0055 \pm 0.0003$ \\
\hline JRNT & $-0.0272 \pm 0.0006$ & $-0.0055 \pm 0.0007$ & $-0.0043 \pm 0.0003$ \\
\hline KROM & $-0.0284 \pm 0.0006$ & $-0.0070 \pm 0.0007$ & $-0.0065 \pm 0.0003$ \\
\hline KUAL & $-0.0277 \pm 0.0006$ & $-0.0002 \pm 0.0007$ & $-0.0052 \pm 0.0003$ \\
\hline MUAD & $-0.0281 \pm 0.0006$ & $-0.0069 \pm 0.0007$ & $-0.0055 \pm 0.0003$ \\
\hline PDIC & $-0.0291 \pm 0.0006$ & $-0.0036 \pm 0.0007$ & $-0.0043 \pm 0.0003$ \\
\hline PUPK & $-0.0299 \pm 0.0006$ & $0.0008 \pm 0.0007$ & $-0.0061 \pm 0.0003$ \\
\hline SEG1 & $-0.0268 \pm 0.0006$ & $-0.0115 \pm 0.0007$ & $-0.0052 \pm 0.0003$ \\
\hline AVERAGE & $-0.0281 \pm 0.0006$ & $-0.0046 \pm 0.0007$ & $-0.0053 \pm 0.0003$ \\
\hline \multicolumn{4}{|c|}{ East Malaysia } \\
\hline BEAU & $-0.0246 \pm 0.0006$ & $-0.0129 \pm 0.0007$ & $-0.0097 \pm 0.0003$ \\
\hline BELU & $-0.0252 \pm 0.0006$ & $-0.0135 \pm 0.0007$ & $-0.0105 \pm 0.0003$ \\
\hline BIN1 & $-0.0261 \pm 0.0006$ & $-0.0086 \pm 0.0007$ & $-0.0090 \pm 0.0003$ \\
\hline KAPI & $-0.0278 \pm 0.0006$ & $-0.0139 \pm 0.0007$ & $-0.0120 \pm 0.0003$ \\
\hline KENI & $-0.0257 \pm 0.0006$ & $-0.0137 \pm 0.0007$ & $-0.0091 \pm 0.0003$ \\
\hline KUDA & $-0.0278 \pm 0.0006$ & $-0.0120 \pm 0.0007$ & $-0.0110 \pm 0.0003$ \\
\hline MRDI & $-0.0243 \pm 0.0006$ & $-0.0181 \pm 0.0007$ & $-0.0095 \pm 0.0003$ \\
\hline MRDU & $-0.0261 \pm 0.0006$ & $-0.0086 \pm 0.0007$ & $-0.0090 \pm 0.0003$ \\
\hline NIAH & $-0.0264 \pm 0.0006$ & $-0.0086 \pm 0.0007$ & $-0.0090 \pm 0.0003$ \\
\hline RANA & $-0.0274 \pm 0.0006$ & $-0.0117 \pm 0.0007$ & $-0.0108 \pm 0.0003$ \\
\hline SARA & $-0.0296 \pm 0.0006$ & $-0.0095 \pm 0.0007$ & $-0.0098 \pm 0.0003$ \\
\hline SEMA & $-0.0287 \pm 0.0006$ & $-0.0084 \pm 0.0007$ & $-0.0089 \pm 0.0003$ \\
\hline TMBN & $-0.0254 \pm 0.0006$ & $-0.0103 \pm 0.0007$ & $-0.0109 \pm 0.0003$ \\
\hline UMAS & $-0.0281 \pm 0.0006$ & $-0.0095 \pm 0.0007$ & $-0.0089 \pm 0.0003$ \\
\hline UMSS & $-0.0232 \pm 0.0007$ & $-0.0156 \pm 0.0008$ & $-0.0073 \pm 0.0003$ \\
\hline AVERAGE & $-0.0264 \pm 0.0006$ & $-0.0117 \pm 0.0007$ & $-0.0097 \pm 0.0003$ \\
\hline
\end{tabular}

Table 6. The time-dependent 3-parameter datum transformation model values for East Malaysia with its selected common points

\subsection{The validation of the time-dependent 3-parameter Helmert datum transformation model}

The validation is carried out at three epochs: 2014.5912 epoch is aligned to IGb08, i.e., processed/combined coordinates. Then, compared to the transformed coordinates via the model in equation (1). The comparison is carried out by analysing the average Helmert residuals which gives the average coordinates differences after 'alignment' between the processed/combined and transformed coordinates. (9/7/14), 2015.2479 (1/4/15), and 2015.4973 (1/7/15). Each

Table 7. Averaged velocities in Cartesian system for Peninsular and East Malaysia. These averaged velocities will then be directly used in equation (1), the time-dependent 3-parameter datum transformation model, in section 2.6

The 'alignment' value is the 3 translation parameters, whereby the smaller the better - good agreement between the 2 coordinate sets. This 'alignment' uses the same common points from table 5 and 6 for Peninsular and East Malaysia, respectively. Generally, if the average Helmert residuals is large, it indicates that some stations does not 'align' well between both coordinate sets. Thus, though the alignment may have close-to-zero translation values, it does not mean all stations, primarily the non-common points, would agree well. Table 8 and 9 provides the average (avg.) and maximum (max.) Helmert residual in local system (sys.) and the translation values for each of the validation epochs for Peninsular and East Malaysia, respectively. The maximum Helmert residuals are given based on the station with the highest value for each local system component. Note that HR is the acronym for Helmert Residuals in table 8. Based on table 8, Peninsular Malaysia stations have significantly small average Helmert residuals which suggests that most stations agree well with datum transformation model coordinate results. However, it seems station TOKA has local issues which results in large Helmert residuals. If TOKA is considered an outlier, the maximum residual would be $1.2 \mathrm{~cm}$ due to station CENE at epoch 2015.4973. As for the translation parameters, only epoch 2015.2479 has a large TY value. This stems from the processing quality, whereby the ambiguity resolution was below $70 \%$, i.e., lower accuracy results. Note that ambiguity resolution should be above $75 \%$ for good accuracy results. All in all, the model's accuracy over Peninsular Malaysia is within centimetre-level, i.e., taking into account the maximum Helmert residuals. 


\begin{tabular}{|c|c|c|c|}
\hline \multicolumn{5}{|c|}{ Epoch 2014.5912 (9/7/14) } \\
\hline Local sys. & North (mm) & East (mm) & Up (mm) \\
\hline Avg. HR & 0.6 & 2.1 & 1.2 \\
\hline Max. HR & $6.0(\mathrm{GAJA})$ & $18.9(\mathrm{TOKA})$ & $14.8(\mathrm{SETI})$ \\
\hline \multirow{2}{*}{$\begin{array}{c}\text { Translation } \\
\text { Parameters }\end{array}$} & TX (mm) & TY (mm) & TZ (mm) \\
\cline { 2 - 4 } & $2.2 \pm 1.0$ & $1.7 \pm 1.0$ & $1.9 \pm 1.0$ \\
\hline \multicolumn{4}{|c|}{ Epoch 2015.2479 (1/4/15) } \\
\hline Local sys. & North (mm) & East (mm) & Up (mm) \\
\hline Avg. HR & 0.8 & 2.3 & 0.6 \\
\hline Max. HR & $9.0(\mathrm{TOKA})$ & $22.9(\mathrm{TOKA})$ & $17.4(\mathrm{TOKA})$ \\
\hline \multirow{2}{*}{$\begin{array}{c}\text { Translation } \\
\text { Parameters }\end{array}$} & TX (mm) & TY (mm) & TZ (mm) \\
\cline { 2 - 4 } & $2.3 \pm 1.4$ & $8.5 \pm 1.4$ & $1.6 \pm 1.4$ \\
\hline \multicolumn{4}{|c|}{ Epoch 2015.4973 (1/7/15) } \\
\hline Local sys. & North (mm) & East (mm) & Up (mm) \\
\hline Avg. HR & 0.5 & 2.9 & 0.6 \\
\hline Max. HR & $11.8(\mathrm{CENE})$ & $25.0(\mathrm{TOKA})$ & $23.0(\mathrm{TOKA})$ \\
\hline \multirow{2}{*}{$\begin{array}{c}\text { Translation } \\
\text { Parameters }\end{array}$} & TX (mm) & TY (mm) & TZ (mm) \\
\cline { 2 - 4 } & $1.3 \pm 1.2$ & $3.5 \pm 1.2$ & $-1.3 \pm 1.2$ \\
\hline
\end{tabular}

Table 8. The average and maximum Helmert residual in local system and the translation values for each of the validation epochs for Peninsular Malaysia

\begin{tabular}{|c|c|c|c|}
\hline \multicolumn{4}{|c|}{ East Malaysia } \\
\hline \multicolumn{4}{|c|}{ Epoch 2014.5912 (9/7/14) } \\
\hline Local sys. & North $(\mathrm{mm})$ & East $(\mathrm{mm})$ & Up (mm) \\
\hline Avg. HR & 0.1 & 0.8 & 2.0 \\
\hline Max. HR & $-3.2(\mathrm{LAB} 1)$ & $3.7(\mathrm{MRDI})$ & $16.7(\mathrm{LAWS})$ \\
\hline \multirow{2}{*}{$\begin{array}{c}\text { Translation } \\
\text { Parameters }\end{array}$} & TX (mm) & TY (mm) & TZ (mm) \\
\cline { 2 - 4 } & $-2.4 \pm 0.9$ & $-2.2 \pm 0.9$ & $0.0 \pm 0.9$ \\
\hline \multicolumn{4}{|c|}{ Epoch 2015.2479 (1/4/15) } \\
\hline Local sys. & North (mm) & East (mm) & Up (mm) \\
\hline Avg. HR & 0.1 & 0.7 & 1.1 \\
\hline Max. HR & $7.6(\mathrm{MRDI})$ & $21.0(\mathrm{MRDI})$ & $26.7(\mathrm{LAWS})$ \\
\hline Translation & TX (mm) & TY (mm) & TZ (mm) \\
\cline { 2 - 4 } Parameters & $3.0 \pm 1.8$ & $-6.6 \pm 1.8$ & $4.6 \pm 1.8$ \\
\hline \multicolumn{4}{|c|}{ Epoch 2015.4973 (1/7/15) } \\
\hline Local sys. & North (mm) & East (mm) & Up (mm) \\
\hline Avg. HR & 0.4 & 1.1 & 1.7 \\
\hline Max. HR & $7.3(\mathrm{LAB} 1)$ & $10.5(\mathrm{RANA})$ & $20.8(\mathrm{MUKA})$ \\
\hline Translation \\
Parameters & TX (mm) & TY (mm) & TZ (mm) \\
\cline { 2 - 4 } & $-4.8 \pm 1.2$ & $-5.4 \pm 1.2$ & $1.3 \pm 1.2$ \\
\hline
\end{tabular}

Table 9. The average and maximum Helmert residual in local system and the translation values for each of the validation epochs for East Malaysia

Based on table 9, East Malaysia has smaller average Helmert residuals compared to Peninsular Malaysia; most probably due to East Malaysia having a more uniform motion - a more conformal transformation. As for the maximum residuals, certain stations seems to exhibit local issues. If none are regarded as outliers, then the maximum residuals is $2.1 \mathrm{~cm}$ from MRDI at epoch 2015.2479 for the North, East (horizontal) component only. However, this falls on the epoch which has lower accuracy results. As for the translation parameters, the values are slightly larger than Peninsular Malaysia which may stem from the datum transformation model being less accurate over East Malaysia; which is mainly due to the geometry of the common points chosen - further studies are required for this region. All in all, the model's accuracy over East Malaysia is within centimetre-level as well.
It is difficult to set an exact standard accuracy value for this time-dependent 3-parameter Helmert datum transformation model; mainly, due to three reasons: (1) the period for estimating the rates of change of the 3 parameters is only 2 years and 3 months which is not sufficient for reliable velocities since the time series has seasonal effects, (2) only 2 single days were chosen as the validation epochs, hence it is not adequate for more accurate coordinate results, and most importantly, (3) the model has not been tested on practical observation data, which requires interpolation for the distortion model to be used effectively. Therefore, the model still has a few unresolved issues which needs to be further studied. Nonetheless, if an accuracy was given, the safest value would be below $3 \mathrm{~cm}$ up to year 2015 for the horizontal component, as the maximum Helmert residuals would certainly not amount to above $3 \mathrm{~cm}$. In general, the model achieved its purpose of transforming coordinates to any future epoch from the reference epoch 2013.5027 (3/7/2013), within an acceptable centimetre-level accuracy, by employing long-term local tectonic motion velocities.

\section{CONCLUSION AND FINAL REMARKS}

The objective of this paper has been achieved, whereby the time-dependent 3-parameter Helmert datum transformation model for Malaysia has been developed. Therefore, providing a workable solution for the non-geocentric datum issue of Malaysia. The initial accuracy of the model is below $3 \mathrm{~cm}$ over Malaysia, whereby further studies are required to resolve some issues and limitations of the model before confirming the valid accuracy. These issues and limitations are the length of period used for estimating the parameters' rates of change, unavailability of 2015 (whole year) GPS data to determine reliable coordinate sets for the validation epochs, and the ability of the model to only carry out forward transformations after epoch 2013.5027. Nevertheless, the aim of this study is not to produce a perfectly working model, but rather it is to present the concept of which a 3-parameter datum transformation model that employs tectonic motion velocities is feasible for Malaysia.

On the other hand, the sub-objective of this study, i.e., to further improve the tectonic motion analysis by Gill et al. (2015) with the addition of 2014 MyRTKnet data, has been achieved as well. With the additional data, the effect of the 2012 Northern Sumatra earthquake can be further analysed; whereby the nonuniform motion due to the 2004 Sumatra-Andaman earthquake has been reduced greatly after the 2012 Northern Sumatra earthquake. Nonetheless, the post-seismic motion due to the 2004 earthquake is still be on going; hence, further data after 2014 is needed to study the tectonic motion of Malaysia.

Finally, a few recommendations are outlined from this study: (1) MyRTKnet core stations should be selected, whereby these stations would represent the national geodetic datum as well as fixed common points between datum realizations, (2) the next GDM2000 realization should be aligned with the latest ITRF2014, (3) the seasonal effects in the time series requires further attention, whereby removing this systematic effect by modelling would be the preferred approach, of which is a major limitation in this study for better seismic interpretation, and (4) research into other datum transformation and propagation models, such as semi-dynamic datums and grid transformations, which comprehensively considers the complex tectonic motion of Malaysia and may yield better accuracy results. 


\section{ACKNOWLEDGEMENTS}

The authors would like to express our gratitude to the Department of Survey and Mapping Malaysia for providing the MyRTKnet data which was essential for conducting this study. The authors would also like to express our sincerest appreciation to MOHE, UTM Research University Grant (RUG), Vote No. 12H99 and 11J21 for funding this study. Lastly, the authors would like to thank our fellow researches who contributed, directly or indirectly, to the knowledge of this study.

\section{REFERENCES}

Blewitt, G. and Lavallée, D., 2002. Effect of annual signals on geodetic velocity. Journal of Geophysical Research: Solid Earth, 107(B7).

Collier, P., 2002. Development of Australia's National GDA94 Transformation Grids. Consultant's Report to the Intergovernmental Committee on Surveying and Mapping, University of Melbourne, Australia.

Dach, R., Hugentobler, U., Fridez, P., \& Meindl, M., 2007. Bernese GPS Software Version 5.0. Switzerland: Astronomical Institute, University of Bern.

Gianniou, M., 2010. The EUREF GR 2007 Campaign. Proceedings in the EUREF Symposium 2010. 2-5 June, Gävle, Sweeden.

Gill, J., Shariff, N. S., Omar, K., and Amin, Z. M., 2015. Tectonic motion of Malaysia: Analysis from years 2001 to 2013, ISPRS Annals of the Photogrammetry, Remote Sensing and Spatial Information Sciences, Vol. II-2/W2, pp. 199-206. Copernicus Publications.

Goudarzi, M. A., Cocard, M., Santerre, R., \& Woldai, T., 2013. GPS interactive time series analysis software. GPS solutions, 17(4), pp. 595-603.

Habrich, H., 2007. "EUREF Regional Densification of ITRF2005. IAG Sub-commission for the European Reference Frame (EUREF)”, ftp://epncb.oma.be/pub/general/EUREF DensificationITRF2005.pdf (20 May 2016).

Mateo, M. L., and Mackern, M. V., 2012. Adjustment Methodology in a Regional Densification of a Terrestrial Reference Frame. INTECH Open Access Publisher.

Mitsakaki, C., 2004. Coordinate Transformations. Proceedings in the FIG Working Week 2004. 22-27 May, Athens, Greece.

Rebischung, P. (2012). “[IGSMAIL-6663] IGb08: An Update on IGS08”, https://igscb.jpl.nasa.gov/pipermail/igsmail/2012/ 007853 (4 May 2016).

Shariff, N. S., Musa, T. A., Omar, K., \& Othman, R., 2014. The Geocentric Datum of Malaysia: Preliminary Assessment and Implications. In Geoinformation for Informed Decisions, pp. 71-83. Springer International Publishing.

Stanaway, R., and Roberts, C., 2009. A Simplified Parameter Transformation Model from ITRF2005 to any Static Geocentric Datum (e.g. GDA94). Proceedings in the IGNSS2009. 1-3 December, Australia.
USGS, 2016. "Significant Earthquakes Archive”, http://earthquake.usgs.gov/earthquakes/eqinthenews/ (16 June 2016).

Wessel, P., \& Smith, W. H. F., 1998. New version of the generic mapping tools released, Eos Trans. AGU, 79(47), pp. 579. 